Informes de la Construcción

Vol. 63, 523, 5-20,

julio-septiembre 2011

ISSN: 0020-0883

elSSN: 1988-3234

doi: 10.3989/ic.10.046

\title{
Construcción con tierra en el siglo XXI
}

\section{Earthen construction in the 21 rst century}

\author{
$\underline{\text { S. Bestraten }}{ }^{(*)}$, E. Hormías ${ }^{(* *)}$, A. Altemir ${ }^{(*)}$
}

\section{RESUMEN}

La construcción con tierra durante la primera década del siglo XXI ha resurgido en todo el mundo como un material con propiedades sostenibles, de bajo impacto ambiental y de gran capacidad expresiva. Se ha experimentado un crecimiento a nivel de proyectos e investigaciones sobre el material relacionado con el aumento de número de asociaciones, instituciones, universidades y eventos alrededor de este sector. Los proyectos actuales han sabido modernizar las técnicas tradicionales de construcción con tierra para adaptarlas a las necesidades proyectuales y constructivas, siendo ampliamente reconocidos por su calidad.

El objetivo de este artículo es ofrecer una visión actual sobre la construcción con tierra a nivel internacional, aportando datos técnicos de su utilización en proyectos arquitectónicos contemporáneos.

$113-96$

Palabras clave: construcción con tierra, materiales sostenibles, innovación, tapial, adobe.

\section{SUMMARY}

Earthen construction during the 21rst century first decade has resurfaced worldwide as a sustainable, low environmental impact and great expressive material. The research and the number of projects has been increased related to the growth of the associations, institutions, universities and events surrounding this sector. These projects have managed to modernize the traditional techniques of building with earth in order to adapt them to today's projecting needs, and have been widely recognized for its quality.

The aim of this article is to provide a global view on earth construction internationally, providing technical data of its utilization in contemporary architectural projects.

Keywords: earthen construction, sustainable materials, innovation, rammed earth, adobe.

\footnotetext{
(*) Universitat Politècnica de Catalunya E.T.S.A.B, Barcelona (España)

(**) Universitat Politècnica de Catalunya E.P.S.E.B, Barcelona (España)

Persona de contacto/Corresponding author: sandra.bestraten@upc.edu (S.Bestraten)
}

Fecha de recepción: 03-06-10 Fecha de aceptación: 30-07-10 


\section{INTRODUCCIÓN}

A las puertas de la actual visión de la arquitectura sostenible, es obligado recuperar la tierra cruda como material de construcción; tan conocido y validado por la historia como también casi olvidado por el progreso del siglo XX. El objetivo de este artículo es ofrecer una visión actual sobre la construcción con tierra, aportando datos técnicos y ejemplos reconocidos de la aplicación de estas técnicas emergentes en todo el mundo.

\section{MARCO NORMATIVO}

El desarrollo en la última década de las normativas que regulan actualmente la construcción, en muchos casos no ha incluido las técnicas de la tierra. Algunos países han desarrollado normativas específicas, especialmente en aquellos lugares donde la tradición o la autoconstrucción ha derivado en un uso habitual de este material.

En España la normativa referente a la tierra se encuentra actualmente en proceso de redacción. En 2010 AENOR publicó la norma UNE 41410:2008 sobre las definiciones, especificaciones y métodos de ensayo de los bloques de tierra comprimida. Posteriormente se desarrollarán las UNE de adobe y tapial. Así mismo a través del Ministerio de la Vivienda y el Instituto de Ciencias de la Construcción Eduardo Torroja se está elaborando un documento como guía para el cumplimiento del Código Técnico de la Edificación en los edificios de tierra.

Sin embargo, el Código Técnico, que regula actualmente la construcción en España, citando un artículo de Eloy Algorri (1), "es un documento de prestaciones. Es decir, impone unos objetivos pero deja libertad de

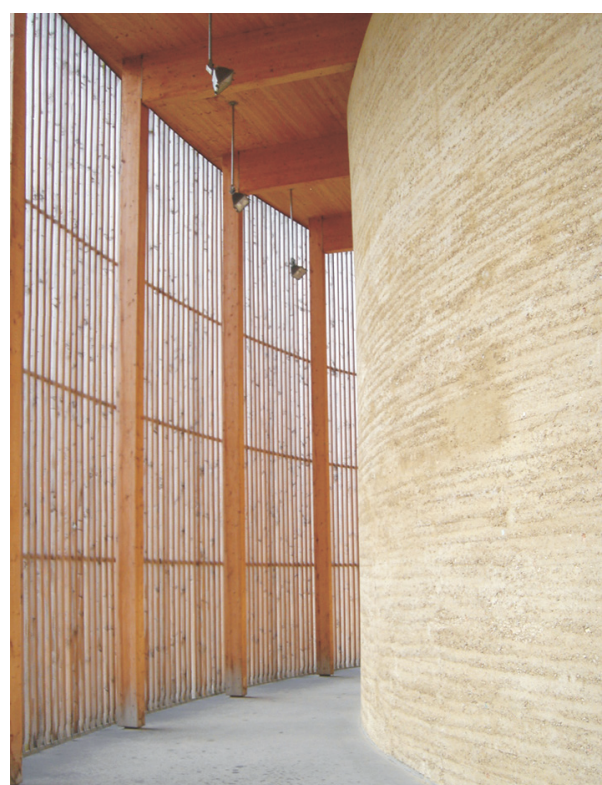

medios para su consecución aunque, para facilitar las cosas, provee una especie de recetarios que son los llamados Documentos Básicos (DB). También cabe la posibilidad (artículo 5 de la parte 1) de que el proyectista, bajo su responsabilidad y previa conformidad del promotor, adopte soluciones alternativas, entendidas como aquellas que satisfacen las exigencias establecidas aunque no cumplen la literalidad del DB, siempre que se justifiquen documentalmente."

Frente a la comodidad de acogerse a los documentos básicos, está la libertad de justificar soluciones alternativas. Pero esta última opción necesita de conocimientos muy específicos y dificulta en gran medida la proliferación de la arquitectura de tierra en España, especialmente en el caso de la construcción de equipamientos que comportan más dificultades de ejecución y más exigencias normativas. Sin embargo, hay un sector emergente en la construcción con tierra de viviendas unifamiliares generalmente asociadas a clientes con sensibilidad hacia la ecología que consiguen sortear con éxito los escollos de las regulaciones.

\section{CONSTRUCCIÓN ACTUAL CON TIERRA}

La construcción con tierra ha dado un paso adelante en los procesos de fabricación. Con la industrialización de los materiales de tierra se mejoran las características naturales del material y se garantizan unas calidades óptimas para su empleo y puesta en obra, reduciendo los tiempos de ejecución. En los últimos tiempos se ha desarrollado la prefabricación del tapial y la introducción en taller de sistemas de instalaciones dentro de los muros.

Buen ejemplo de la visión de futuro de la construcción con tierra son los equipamientos que se presentan a continuación, con una visión internacional y contemporánea y validados por un conjunto de premios de reconocido prestigio.

\subsection{Tapial}

La técnica del tapial se define como tierra amasada y apisonada en un encofrado para formar muros monolíticos (3).

2000 Capilla de la Reconciliación. Berlín, Alemania. Arquitectos: Reiterman y Sassenroth. Construcción del tapial: Lehm Ton Erde, Martin Rauch.

La antigua iglesia de la reconciliación, situada en la franja que delimita el muro de Berlín, interfería con los trabajos de vigilancia; motivo por el cual en 1985 fue destruida. Una vez derribado el Muro, dos jóvenes 
arquitectos berlineses se ofrecieron para la construcción en el mismo emplazamiento de una Capilla de la Reconciliación en memoria de la antigua iglesia.

El proyecto inicial se basaba en el uso de una doble piel de un muro de hormigón y otro de vidrio. Esta propuesta fue rechazada por la comunidad por considerar estos materiales representativos de la opresión ejercida por el muro que dividía la ciudad. Finalmente, la substitución de los materiales por muros de tierra y celosía de madera hicieron posible el proyecto.

El asesoramiento del reconocido artista y constructor Martin Rauch fue vital para la ejecución del edificio. Con su empresa especializada y la sensibilidad plástica que lo caracterizan ha sido capaz de cambiar la concepción de la tierra. Un material asociado a la tradición e incluso a la pobreza está cambiando hacia una nueva visión moderna. La combinación de los diferentes colores según el tipo de tierra y diferentes texturas según los encofrados ha contribuido a que el muro de tierra sea, además, una obra escultórica.

Actualmente, la Capilla de la Reconciliación de Berlín es un referente a nivel europeo, dado que se trata del primer edificio público con estructura portante de tierra construido en los últimos 150 años en Alemania. A su vez es uno de los reclamos turísticos más visitados de la capital alemana.

Los muros interiores de tierra apisonada son de 7,20 metros de alto, 0,60 m de espesor y $43 \mathrm{~m}$ de longitud. La forma ovalada del conjunto tiene diámetros de entre 10 y 14 metros y soporta las cargas de la cubierta. Debido al hecho de que la técnica de construcción no estaba autorizada, el Departamento de Estructuras Portantes y Construcción de la Technical University de Berlín se encargó del proyecto como un "caso singular de autorización".

Su responsabilidad fue proporcionar un análisis detallado de la tierra apisonada en las fases de fabricación e instalación. Asimismo, durante la fase de construcción proporcionaron una cuidadosa supervisión del proceso. Cabe destacar que hacía muchos años que no se construía un edificio público con estructura de tierra, a pesar de una larga tradición del material también en estas latitudes. Las autoridades municipales y los ingenieros de estructuras de Berlín establecieron unas condiciones de seguridad estructural equivalentes a un coeficiente de seguridad siete veces mayor que para cualquier otro edificio convencional.
En enero de 1999, se realizaron ensayos de diversas muestras de mezclas para averiguar su resistencia a compresión, tracción y cortante. La mezcla que obtuvo los mejores resultados, como se muestra en la siguiente tabla, fue seleccionada para construir la capilla. Se trata de una mezcla de arcilla y gravas de diversas granulometrías con un pequeño porcentaje de fibras de lino añadidas.

Tabla 1

Características del material

\begin{tabular}{|l|c|}
\hline Características del material \\
\hline Contenido inicial de humedad & $8,20 \%$ \\
\hline Retracción & $0,15 \%$ \\
\hline Resistencia a compresión & $3,2 \mathrm{~N} / \mathrm{mm}^{2}$ \\
\hline Módulo de elasticidad & $650 \mathrm{~N} / \mathrm{mm}^{2}$ \\
\hline Resistencia a flexión & $0,63 \mathrm{~N} / \mathrm{mm}^{2}$ \\
\hline Resistencia a cortante & $0,79 \mathrm{~N} / \mathrm{mm}^{2}$ \\
\hline
\end{tabular}

Fuente: Martin Rauch

Para los muros se utilizaron 390 toneladas $\left(160 \mathrm{~m}^{3}\right)$ de tierra mezclada con escombros de la anterior iglesia. Toda la tierra se mezcló de forma homogénea según la muestra seleccionada y fue vertida en los encofrados. La arcilla con su humedad natural se fue colocando en capas de 30 centímetros de grosor en los encofrados y se compactó después a unos 8 centímetros.

Las estructuras portantes de tierra trabajan prácticamente en su totalidad sometidas a esfuerzos de compresión. Su resistencia característica varía según la tecnología, densidad y estabilizantes añadidos.

En referencia a los niveles de resistencia característica de la tierra, las fuentes son muy variables y no se tiene un conocimiento riguroso de los métodos de ensayo. Motivo por el cual es necesario establecer un protocolo de ensayos que ofrezca garantías y que permita reducir los coeficientes de seguridad en los cálculos, del mismo modo que se efectúa con otros materiales.

Tabla 2

Resistencia a compresión simple

\begin{tabular}{|c|c|c|}
\hline material & densidad & $\begin{array}{c}\text { resistencia } \\
\text { a compresión }\end{array}$ \\
\hline *fuente: (4) & $1.200-1.500 \mathrm{~kg} / \mathrm{m}^{3}$ & $0,53-1,72 \mathrm{~N} / \mathrm{mm}^{2}$ \\
\hline cob & $1.615 \mathrm{~kg} / \mathrm{m}^{3}$ & $1 \mathrm{~N} / \mathrm{mm}^{2}$ \\
\hline $\begin{array}{l}\text { btc bloque de tierra } \\
\text { comprimida }\end{array}$ & $1.700-2.000 \mathrm{~kg} / \mathrm{m}^{3}$ & $1-5 \mathrm{~N} / \mathrm{mm}^{2}$ \\
\hline btc estabilizado bioterre (7) & $1.787,5 \mathrm{~kg} / \mathrm{m}^{3}$ & $10,8 \mathrm{~N} / \mathrm{mm}^{2}$ \\
\hline$(2,4,8)$ & $1.900-2.200$ & 3-4 $\mathrm{N} / \mathrm{mm}^{2}$ \\
\hline
\end{tabular}


La resistencia de cálculo $\left(f_{d}\right)$ es igual a su resistencia característica dividida por el coeficiente parcial de seguridad que minora su resistencia $\left(\gamma_{\mathrm{m}}\right)$. El coeficiente de seguridad parcial se puede determinar en función de la variabilidad del material y la calidad de los trabajos, según la siguiente tabla:

Tabla 3

Coeficientes de seguridad

\begin{tabular}{|c|c|c|}
\hline $\begin{array}{l}\text { Categoría } \\
\text { de ejecución }\end{array}$ & $\gamma_{\mathrm{m}}$ & \\
\hline A & $3-4$ & $\begin{array}{l}\text { Los trabajos de obra los ejecutan constructores } \\
\text { especialistas con } \\
\text { experiencia; materiales ensayados y } \\
\text { seleccionados; programa de control } \\
\text { exhaustivo previo y durante la construcción, con } \\
\text { resultados satisfactorios. }\end{array}$ \\
\hline B & $4-5$ & $\begin{array}{l}\text { Los trabajos de obra los ejecutan constructores } \\
\text { no especializados con } \\
\text { supervisión; programa completo de control } \\
\text { previo y durante la } \\
\text { construcción, con resultados satisfactorios. }\end{array}$ \\
\hline$C$ & $5-6$ & $\begin{array}{l}\text { Los trabajos de obra los ejecutan mano de obra } \\
\text { inexperta con supervisión; } \\
\text { programa completo de control previo y durante } \\
\text { la construcción, con } \\
\text { resultados satisfactorios; los materiales se } \\
\text { ajusten marginalmente a los } \\
\text { límites recomendados de los criterios de } \\
\text { idoneidad, las propiedades de los } \\
\text { materiales de los resultados de las pruebas } \\
\text { muestran cierta incoherencia. }\end{array}$ \\
\hline
\end{tabular}

Fuente: elaboración propia a partir de $(6,9)$.

Las resistencias a compresión, aunque bajas, son suficientes para un sector amplio del patrimonio construido, siempre que se tenga en cuenta el grosor de los muros por condicionantes constructivos y que las cargas se transmiten de forma repartida. Los valores característicos para esfuerzos de tracción, flexión y cortante son mínimos para estas tecnologías (entre 0,02 y 0,1 N/mm²), por lo que sería necesario confinar y armar la tierra para dar capacidad de trabajo a tracción en caso de considerarlos a nivel estructural.

Aunque tradicionalmente los muros de tierra han formado parte de la estructura portante de los edificios, el uso actual de paredes de tierra no tiene porqué ser exclusivamente con finalidad estructural. Está demostrada la solvencia del material aplicado a cerramientos de edificios con estructura independiente, como es el caso del siguiente proyecto:
2001 Centro de Visitantes en Eden Project, Cornwall, Reino Unido. Arquitecto: Grimshaw Architects. Construcción del tapial: RamCast, Rowland Keable. Premios:

- LABC National Built In Quality Awards

- Business Commitment to the Environment Award

- World Architecture Award

- AlA London/UK Excellence in Design Award

- BIAT Award for Technical Excellence

- Structural Steel Design Award

- British Construction Industry Award

- RIBA Award

- Stirling Prize Runner Up

El Proyecto Edén ocupa una vieja cantera de caolín cerca de St Austell en Cornualles en el sudoeste de Inglaterra. El enfoque principal del proyecto es la educación a todos los niveles. Los Biomas (invernaderos gigantes, uno de los cuales es el mayor del mundo) y las exhibiciones, proporcionan la base para una institución científica y educativa dedicada al desarrollo sostenible.

El centro de visitantes, comprende dos edificios adyacentes a los biomas. Los largos muros de $45 \mathrm{~m}$ sutilmente curvados de tapial, dan la bienvenida a los visitantes, conduciéndolos a través de una calle parcialmente cubierta por unas estructuras tensadas, definida por un lado con la pared de tapial vista.

Los muros de tierra no tienen función portante, sino únicamente de cerramiento; aunque por su resistencia podrían haber soportado correctamente las cargas. Situados bajo el alero de la cubierta y sobre un zócalo de hormigón, los muros se coronan con una ventana corrida que aporta ligereza al conjunto. De este modo, permite que se construyan los muros de tierra una vez ya ejecutada la cubrición, reduciendo el control durante la ejecución ya que es importante evitar que la tierra se humedezca en exceso, más de lo requerido durante el proceso de obra. La sección trapezoidal de los muros consigue una mayor estabilidad del elemento aunque dificulta su compactación.

El tapial de prueba se llevó a cabo in situ por los contratistas. El suelo se encontró a poca distancia del emplazamiento, en una antigua cantera. La tierra utilizada estaba formada por arcillas de baja expansividad y un alto contenido en áridos. Esta tierra estaba situada a una profundidad de entre 2 y 3 metros, sobre la capa de arcillas de caolín que era el material principal de extracción de la cantera.

Los muros de tapial se construyeron a un ritmo de $7,5 \mathrm{~m}^{2}$ por día, equivalente $4 \mathrm{~m}^{3}$ o 10 toneladas de tierra por día. 
También encontramos en otros ejemplos muros de tapial con estructura portante embebida en los propios muros. Aunque éstos no soporten el peso de la cubierta pueden ejercer la función de arriostramiento general de la estructura. Así se constata en el siguiente edificio.

2002 Centro Nacional del Vino, Adelaide, Australia. Arquitectos: Grieve Gillette y Cox. Constructor: Mitchel Builders. Premios:

- Urban Development Institute of Australia Award for Excellence in Urban Planning 2001

- Australian Timber Design Awards: Public and Commercial Building, Best use of Timber Engineering, Supreme Timber Design Award, 2001

- RAIA (SA Chapter) Award of Merit - New Building, 2002

- AISC Award for Steel Construction ExceIlence, 2002

- Best Architecture Award - 7th World Conference on Timber Engineering - Malaysia, 2002

El Centro Nacional del Vino de Australia se ha desarrollado como un centro cultural para la promoción y reconocimiento del vino. Una serie de galerías de exposición interpretativa forman el núcleo de la experiencia del vino para el público, complementado con salas de degustación, los espacios de la galería de arte visual, un restaurante y la sala de actos.

Los muros de tapial del Centro tienen la estructura metálica embebida en el interior como evidencian las pertinentes juntas estructurales entre materiales. Con aproximadamente 10 metros de altura y 36 metros de longitud, están considerados como los mayores muros de tierra del hemisferio sur (10).

2003 Hall del Bodhi Mandala Zen Center, Jemez Springs, Nuevo México, EE. UU. Arquitectos: Predock Frane Architects.

Nuevo México es el epicentro de la construcción con tierra en Norte América pero la mayoría de edificaciones tradicionalmente se han construido con adobe. Un ejemplo de la arquitectura moderna en tapial es este centro de estudios del Budismo del Bodhi Mandala Zen Center.

El hall combina el uso de materiales naturales, sistemas de climatización pasivos y activos, y la relación entre ligereza y masa para crear un espacio único dedicado al ritual diario de la práctica Zen.

Situado en una zona de clima extremo, el edificio se protege de los saltos térmicos gracias a una de las mejores bondades de la tie- rra: su comportamiento térmico. Los muros de tapial tienen unas propiedades de inercia térmica excelentes, que pueden mantener temperaturas interiores confortables sin necesidad de calefacción o refrigeración mecánicas con el consecuente ahorro energético.

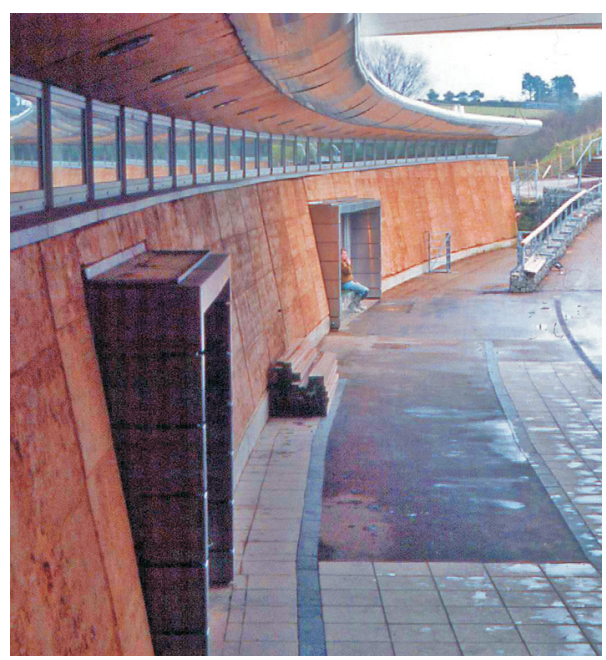
2. Centro de Visitantes en el Eden
Project, Cornwall, Reino Unido.
Fuente: Rowland Keable, Ram Cast $\mathrm{CIC}$

3. Encofrado de madera y construcción del tapial en el Eden Project, Cornwall, Reino Unido, Fuente: Rowland Keable, Ram Cast CIC

Muros de tapial y estructura mixta en el Centro Nacional del Vino, Adelaide, Australia. Fuente: University of Adelaide

5. Muros de tapial y cubierta paraboloide hiperbólica en el Bodhi Mandala Zen Centre, Jemez Springs, Nuevo México. Imagen: Predock Frane Architects
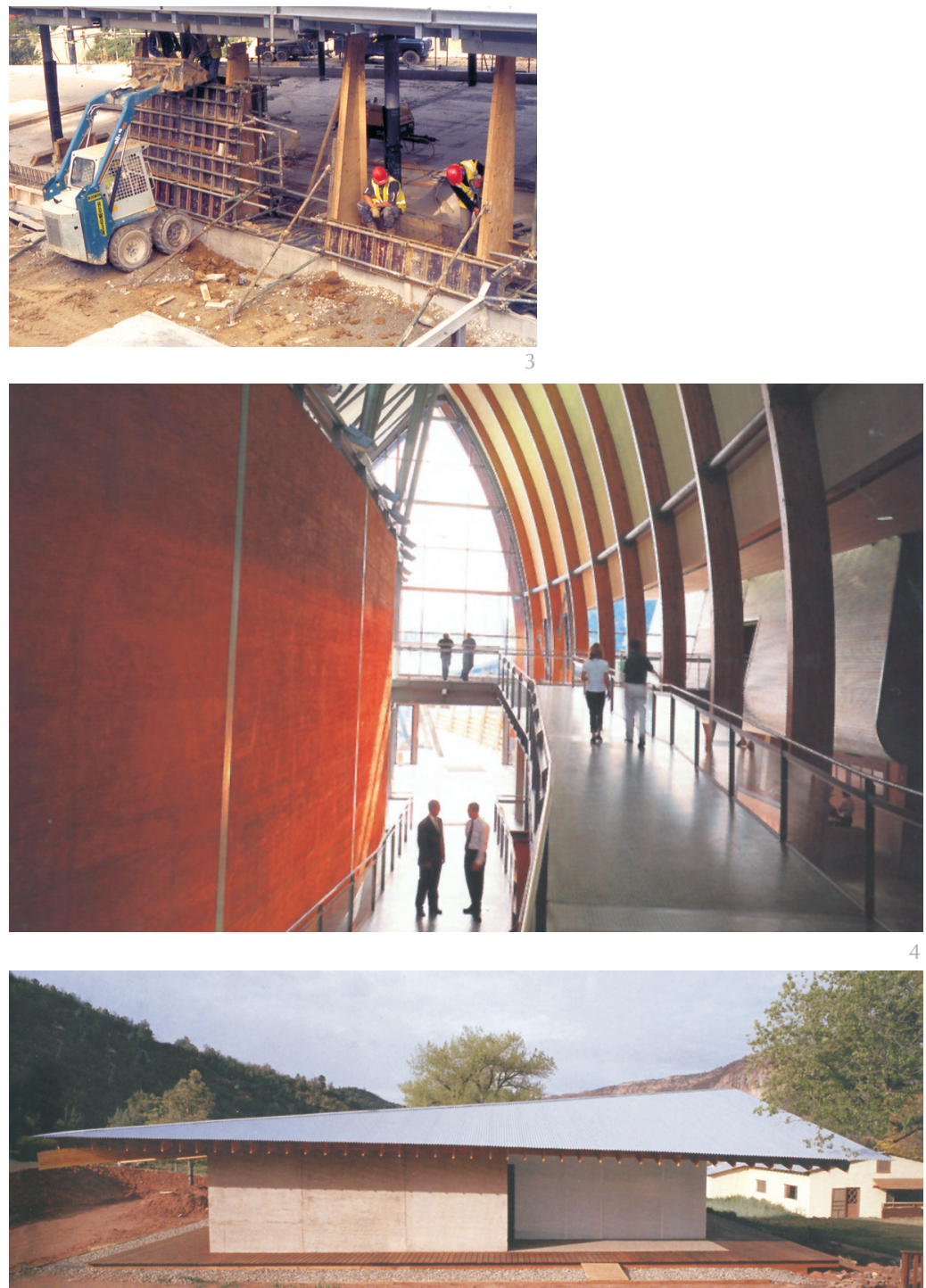
Los muros de tierra tradicionalmente no han requerido ningún tipo de aislamiento añadido ya que aunque su factor $U$ de transmitancia térmica es comparable al de otros materiales convencionales, su masa o inercia térmica permite acumular una gran cantidad de calor. Aun así, la actual normativa comporta cumplir unos valores máximos de transmitancia térmica.

$\mathrm{U}$ en $\mathrm{W} / \mathrm{m}^{2} \mathrm{~K}=1 / \mathrm{Rt}, \quad \mathrm{Rt}=\mathrm{r} 1+\mathrm{r} 2+\sum \mathrm{rm}$ $\mathrm{rm}=\mathrm{t} 1 / \lambda 1$

\section{Donde:}

$r 1$ = resistencia superficial de la cara externa del muro en $\mathrm{m}^{2} \mathrm{~K} / \mathrm{W}$

r2 = resistencia superficial de la cara interna del muro $\mathrm{m}^{2} \mathrm{~K} / \mathrm{W}$

$\sum \mathrm{rm}=$ sumatorio de las resistencias de los distintos componentes del muro en $\mathrm{m}^{2} \mathrm{~K} / \mathrm{W}$ $\mathrm{t} 1=$ espesor del componente en metros

$\lambda 1=$ conductividad del material del componente en $\mathrm{W} / \mathrm{mk}$

Para muros de tierra, el valor de conductividad térmica varía, según la densidad seca del material, entre $0,46 \mathrm{~W} / \mathrm{mk}$ y $1,60 \mathrm{~W} / \mathrm{mk}$ por lo que los espesores de muro necesarios para cumplir con una conductividad inferior a $0,74 \mathrm{~W} / \mathrm{m}^{2} \mathrm{k}$ sin necesidad de aislante añadido serían de entre 0,70 y 1,10 metros de espesor. No obstante, en la orientación sur, con el espesor tradicional de aproximadamente $40 \mathrm{~cm}$ de los muros de tierra no sería recomendable añadir aislante térmico, ya que en esta orientación se optimiza la inercia térmica.

\section{Tabla 4}

Conductividad de los materiales

\begin{tabular}{|lr|r|c|}
\hline \multicolumn{1}{|l|}{ material } & \multicolumn{1}{c|}{ densidad } & $\begin{array}{c}\text { conductividad } \\
\lambda\end{array}$ \\
\hline tapial & *fuente: $(4,9)$ & $1.400-2.000 \mathrm{~kg} / \mathrm{m}^{3}$ & $0,6 / 1,6 \mathrm{~W} / \mathrm{mk}$ \\
\hline btc & $(4,9)$ & $1.700 \mathrm{~kg} / \mathrm{m}^{3}$ & $0,81 \mathrm{~W} / \mathrm{mk}$ \\
\hline adobe & $(11,12)$ & $1.200 \mathrm{~kg} / \mathrm{m}^{3}$ & $0,46 \mathrm{~W} / \mathrm{mk}$ \\
\hline hormigón armado & $(13)$ & $2.300-2.500 \mathrm{~kg} / \mathrm{m}^{3}$ & $2,3 \mathrm{~W} / \mathrm{mk}$ \\
\hline hormigón en masa in situ & $(13)$ & $2.000-2.300 \mathrm{~kg} / \mathrm{m}^{3}$ & $1,65 \mathrm{~W} / \mathrm{mk}$ \\
\hline bloque de hormigón convencional (13) & $860 \mathrm{~kg} / \mathrm{m}^{3}$ & $0,91 \mathrm{~W} / \mathrm{mk}$ \\
\hline pared de ladrillo macizo & $(13)$ & $2.170 \mathrm{~kg} / \mathrm{m}^{3}$ & $1,04 \mathrm{~W} / \mathrm{mk}$ \\
\hline pared de ladrillo hueco & $(13)$ & $670 \mathrm{~kg} / \mathrm{m}^{3}$ & $0,22 \mathrm{~W} / \mathrm{mk}$ \\
\hline
\end{tabular}

El siguiente ejemplo es un caso de incorporación de aislamiento térmico en el tapial, para combinar los beneficios de la masa térmica y mejorar la transmitancia:
2008 Biblioteca Sublette County, Pinedale, Wyoming, EE. UU. Arquitectos: Carney Architects Construcción del tapial: Terra Firma Builders.

Premios:

- 2009 Citation Award, AlA Western Mountain Region Chapter

- 2008 Merit Award, AIA Wyoming Chapter

En 2008 se decidió ampliar el edificio principal de la Bilbioteca de Sublette County con una nueva ala de $8.500 \mathrm{~m}^{2}$. El nuevo edificio está situado entre la antigua biblioteca y el parque de bomberos, por lo que conforma un edificio largo y estrecho con un salón de actos, galería, biblioteca de la colección occidental y oficinas administrativas.

Este edificio consta, según sus arquitectos, como el primer edificio público moderno de Estados Unidos en usar tapial con aislante como material de construcción. Respondiendo a la demanda del equipo director de la biblioteca de diseñar un edificio lo más sostenible posible, el arquitecto John Carney recomendó el uso de tapial para los muros exteriores e interiores del edificio.

La tierra apisonada fue seleccionada por sus cualidades térmicas, el uso de materiales locales y por su calidad táctil, para lograr la máxima eficiencia energética en un clima extremo de gran altitud.

El sistema de tapial utilizado se denomina Sirewall, (tapial estabilizado y con aislamiento), una patente de Terra Firma Builders. Este sistema en sandwich tiene la particularidad de incluir barras de refuerzo de acero corrugado para fijar el aislamiento de poliestireno extruido de $10 \mathrm{~cm}$ de ancho en el interior del tapial, recubierto por una hoja exterior de tierra de $17,5 \mathrm{~cm}$ de ancho y otra interior de $25 \mathrm{~cm}$. La transmitancia térmica del aislamiento interior es de $0,03 \mathrm{~W} / \mathrm{m}^{2 \circ} \mathrm{C}$, lo que sumado a la inercia térmica de la tierra garantiza el confort necesario para la biblioteca.

La mezcla de la tierra utilizada está formada por una selección de tierras con una buena granulometría. Contenía un 10\% de cemento portland y óxido de hierro para realzar el color ocre. La mezcla se compactó mediante un pisón neumático con una cabeza de 10 $\mathrm{cm}$ de diámetro y el contenido de humedad se controlaba mediante el drop test. La mezcla se compacta por capas de $15 \mathrm{~cm}$ de altura hasta completar los muros de 4 metros de altura media.

Según datos del constructor, el promedio de valores de resistencia a la compresión es de $2,9 \mathrm{~N} / \mathrm{mm}^{2}$, con algunos resultados superiores a $4,1 \mathrm{~N} / \mathrm{mm}^{2}$. 
En una biblioteca, el comportamiento frente al fuego de los materiales de construcción es especialmente importante. La tierra como material se considera prácticamente incombustible, no propaga el fuego y no emite gases tóxicos. La resistencia al fuego de los muros de tierra se debe considerar de REI 90 para espesores iguales o mayores a $150 \mathrm{~mm}$, con lo que es equivalente a la resistencia de otros materiales convencionales.

2010 Centro para la Tecnología Alternativa, Machynleth, Gales, Reino Unido.

Arquitectos: Pat Borer and David Lea. Construcción del tapial: RamCast, Rowland Keable.

Este equipamiento educativo que se inauguró en Junio de 2010 para la formación de profesionales de la sostenibilidad, está situado en Machynleth, Gales. El salón de actos del Centre for Alternative Techonoly, muestra los beneficios de la construcción con tierra. Los impresionantes muros de 7,2 metros de altura y $50 \mathrm{~cm}$ de espesor, soportan las cargas de la cubierta. La forma curva de 15 metros de diámetro de los muros encareció notablemente el coste de los encofrados.

Con el propósito de ahorrar energía y cemento en la construcción, se proyectó el salón de actos con muros de tapial y el resultado es un edificio con unas propiedades higrotérmicas que reducen las necesidades de climatización mecánica, algo idóneo para un edificio con una supuesta alta demanda de calefacción como éste.

Uno de los aspectos clave en el salón de actos es el comportamiento acústico de sus paramentos. La cualidad de aislamiento acústico de un muro se debe a la densidad o "masa" $\left(\rho^{\prime}, \mathrm{kg} / \mathrm{m}^{2}\right)$. Los muros de tierra, por su alta densidad, presentan un aislamiento acústico muy favorable. El valor de aislamiento frente a sonido aéreo, $\mathrm{Ra}$, para paredes de tierra se obtiene mediante:

$\mathrm{Ra}=21,65 \log 10 \cdot \rho^{\prime}-2,3\left(\right.$ para $\left.\rho^{\prime}>50 \mathrm{~kg} / \mathrm{m}^{2}\right)$

Donde:

$\rho^{\prime}=\rho \times t$

$\rho=$ densidad del muro de $\mathrm{kg} / \mathrm{m}^{3}$

$\mathrm{t}=$ espesor del muro en metros

Para una pared de tierra de entre 150 y 1200 $\mathrm{mm}$ de espesor, Ra varía generalmente, como resultado de las diferentes densidades logradas, entre 49 y $70 \mathrm{~dB}$, cumpliendo con las normativas actuales de aislamiento acústico.

Para muros de $30 \mathrm{~cm}$, el nivel de aislamiento es equivalente a otros materiales convencionales (9).
Tabla 5

Comportamiento frente al fuego

\begin{tabular}{|l|c|c|}
\hline material & espesor (m) & REI (min) \\
\hline muros de tierra *fuente: (9) & 0,15 & 90 \\
\hline hormigón armado (14) & 0,16 & 90 \\
\hline $\begin{array}{l}\text { bloque de hormigón convencional espesor } \\
200 \mathrm{~mm}(14)\end{array}$ & 0,2 & 120 \\
\hline pared de ladrillo macizo o perforado (14) & $0,11 / 0,20$ & 120 \\
\hline
\end{tabular}
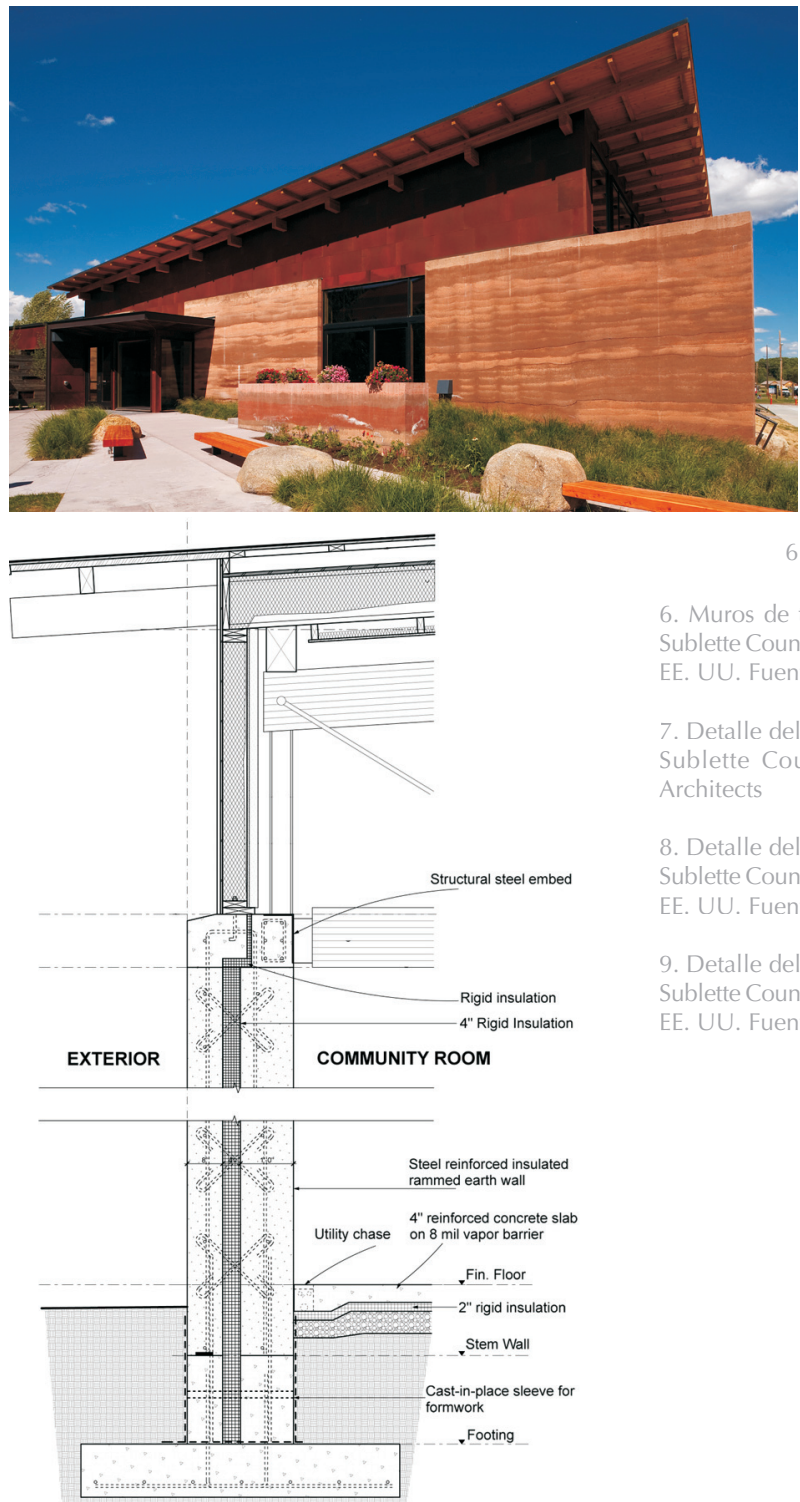

6. Muros de tapial en la Biblioteca Sublette County, Pinedale, Wyoming EE. UU. Fuente: Carney Architects

Detalle del muro en la Biblioteca Sublette County. Fuente: Carney Architects

8. Detalle del muro en la Biblioteca Sublette County, Pinedale, Wyoming, EE. UU. Fuente: Victor Tvedten

9. Detalle del muro en la Biblioteca Sublette County, Pinedale, Wyoming, EE. UU. Fuente: Victor Tvedten
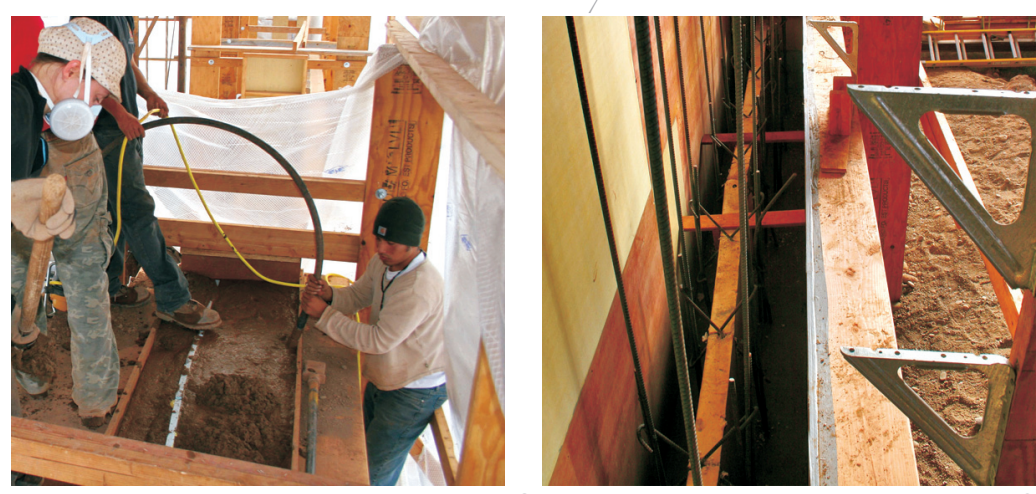
Tabla 6

Comportamiento acústico de los materiales

\begin{tabular}{|c|c|c|c|}
\hline material & densidad & espesor (m) & $R a(d B)$ \\
\hline$*_{\text {fuente: }}(9)$ & $2.000 \mathrm{~kg} / \mathrm{m}^{3}$ & 0,30 & 57,85 \\
\hline btc & $1.700 \mathrm{~kg} / \mathrm{m}^{3}$ & 0,30 & 56,32 \\
\hline Adobe & $1.200 \mathrm{~kg} / \mathrm{m}^{3}$ & 0,30 & 53,04 \\
\hline hormigón armado & $2.300 \mathrm{~kg} / \mathrm{m}^{3}$ & 0,30 & 59,16 \\
\hline hormigón en masa in situ & $2.000 \mathrm{~kg} / \mathrm{m}^{3}$ & 0,30 & 57,85 \\
\hline $\begin{array}{l}\text { bloque de hormigón convencional } \\
\text { espesor } 200 \mathrm{~mm}\end{array}$ & $860 \mathrm{~kg} / \mathrm{m}^{3}$ & 0,20 & 46,10 \\
\hline pared de ladrillo macizo & $2.170 \mathrm{~kg} / \mathrm{m}^{3}$ & 0,30 & 58,61 \\
\hline pared de ladrillo hueco & $670 \mathrm{~kg} / \mathrm{m}^{3}$ & 0,30 & 47,56 \\
\hline
\end{tabular}
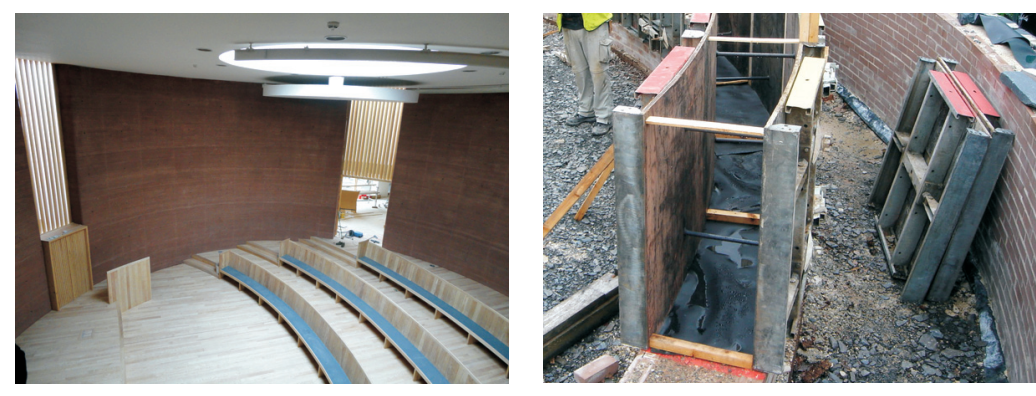

10. Muros de tapial y lucernario de cubierta en el Centro para la Tecnología Alternativa, Gales, Reino Unido. Fuente: Rowland Keable, Ram Cast $\mathrm{CIC}$

11. Detalle de encofrado, impermeabilización y cimentaciones en el Centro para la Tecnología Alternativa, Gales, Reino Unido. Fuente: Rowland Keable, Ram Cast CIC

12. Muros y cubierta de BTC en la sala polivalente de la Escuela Deepanam, Auroville, India. Fuente: Auroville Earth Institute

13. Muros y cubierta de BTC en a sala polivalente de la Escuela Deepanam, Auroville, India. Fuente: Auroville Earth Institute

\subsection{BTC bloque de tierra comprimida}

El bloque de tierra comprimido se caracteriza por ser un paralelepípedo de tierra que se prensa mecánicamente, suele llevar una pequeña proporción de cal o cemento y se deja secar al aire para formar muros de fábrica.

Conocido como BTC estabilizado, podríamos decir que el BTC es un tapial confinado en tamaños pequeños pero las dosificaciones, así como el contenido de humedad y la presión aplicada en el proceso de ejecución son semejantes.
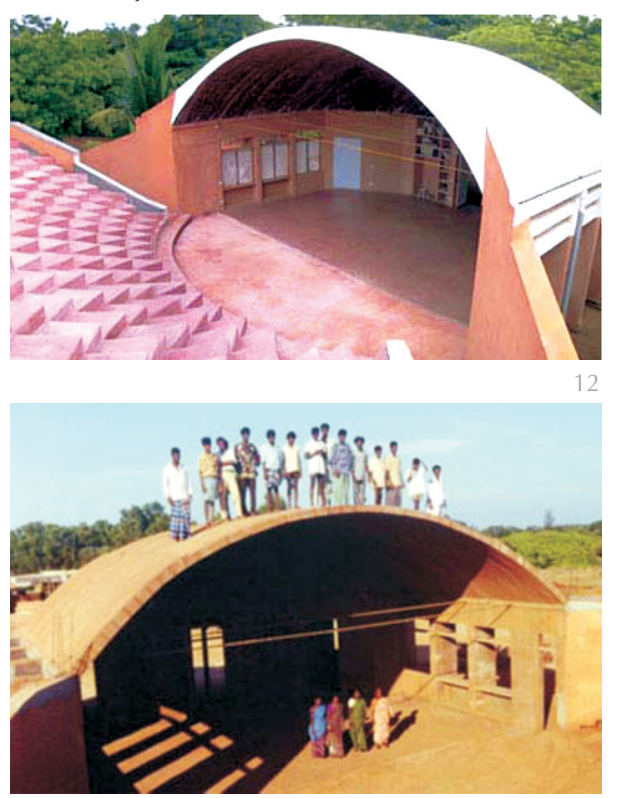

1995 Deepanam School, Auroville, India. Auroville Earth Institute. Cátedra Unesco en Arquitectura de tierra.

El Instituto de la Tierra de Auroville trabaja en la investigación, desarrollo, promoción y transferencia de las tecnologías basadas en la tierra. La tecnología que más se promueve es la del bloque de tierra compactado y estabilizado. Estas tecnologías se difunden a través de cursos de formación, seminarios, talleres, manuales y documentos. El método de difusión más efectivo es la construcción de los edificios del propio centro con este material.

La sala polivalente de la escuela Deepanam de Auroville, fue construida en 1995 y representa la oportunidad de mostrar cómo la técnica de bóvedas Nubias, realizadas tradicionalmente con tierra, puede utilizarse para espacios de grandes luces. Está formada por un escenario cubierto con una bóveda de 10,35 metros de luz, con un grosor de 17,7 $\mathrm{cm}$ y fue construida en tres semanas por cuatro operarios.

La bóveda se realizó con bloques de tierra comprimida y estabilizada mediante el sistema Auram de prensas manuales desarrollado en Auroville.

La prensa Auram 3000, aunque manual, alcanza un índice de compresión muy alto de 1,60 hasta 1,83 con $150 \mathrm{KN}$ de fuerza disponible. El alto índice de compresión alcanzado por la prensa produce bloques con una elevada resistencia a compresión.

El micro-ajuste de la tapa asegura bloques muy precisos, con menos de $1 \mathrm{~mm}$ de tolerancia en su altura. Esta homogeneidad de las piezas permite ahorrar mortero. Los bloques solamente necesitan entre 0,5 y $1 \mathrm{~cm}$ de mortero de tierra estabilizada para su agarre.

Las medidas más habituales del BTC son $10 \times 15 \times 30 \mathrm{~cm}$. La altura de los bloques Auram se puede ajustar en incrementos de $5 \mathrm{~mm}$, para conseguir alturas desde 5 hasta $10 \mathrm{~cm}$.

2000 Centro para la Atención de Gente Invidente, Ciudad de México, México. Arquitecto: Mauricio Rocha.

- Medalla de Plata en la VII bienal de Arquitectura en México

El Centro para personas ciegas es un complejo de $14.000 \mathrm{~m}^{2}$ de equipamientos educativos y de recreo. El campus está situado en Iztapalapa, el barrio con mayor concentración de personas con discapacidad visual de Ciudad de México. 
Debido a un escaso presupuesto, el arquitecto Mauricio Rocha decidió emplear la técnica de los bloques de tierra comprimidos para los muros de cerramiento. Las diferentes texturas de los zócalos de hormigón a la altura de la mano sirven de orientación para los alumnos del centro. Los muros de tierra sirven de piel para la estructura de hormigón armado que soporta la cubierta.

Al confort térmico y acústico anteriormente citados, se suma la calidez táctil de los materiales de la tierra, que aportan un valor añadido como material de construcción.

\subsection{Adobe}

El adobe se basa en una masa de barro, frecuentemente mezclada con paja, moldeada con forma prismática, de tamaño variable y secada al aire para formar muros de fábrica.

La gran diferencia con el tapial y el BTC es la cantidad de agua necesaria en el proceso de fabricación. Esta elevada cantidad de agua que se evapora en su proceso de secado requiere de la presencia de fibras vegetales que evite las fisuraciones por retracción. En el tapial y el BTC, dado que las tierras tienen menor presencia de arcillas y mayor contenido de limos y arenas, sumado a una presencia menor de humedad, hacen normalmente innecesaria la adición de fibras. En las gráficas adjuntas se pueden identificar las variables de caracterización de las tierras.

2002 Bodega en los Robles, San Fernando, Chile. Arquitecto: José Cruz Ovalle.

La elaboración del vino, en estas bodegas de Chile, reúne el cultivo orgánico, el reciclaje de las aguas y el aprovechamiento del material orgánico para compostaje. Así, la masa edificada de estas bodegas se construye con materiales naturales, no sólo por un arcaísmo o ecologismo, sino desde una
Tabla 7

Características de los btc AURAM. Fuente: Auroville Earth Institute

\begin{tabular}{|l|l|l|l|}
\hline Propiedades & Unidad & clase A & clase B \\
\hline resistencia a compresión a los 28 días & $\mathrm{N} / \mathrm{mm}^{2}$ & $5-7$ & $2-5$ \\
\hline resistencia a tracción a los 28 días & $\mathrm{N} / \mathrm{mm}^{2}$ & $1-2$ & $0,5-1$ \\
\hline resistencia a flexión a los 28 días & $\mathrm{N} / \mathrm{mm}^{2}$ & $1-2$ & $0,5-1$ \\
\hline resistencia a cortante a los 28 días & $\mathrm{N} / \mathrm{mm}^{2}$ & $1-2$ & $0,5-1$ \\
\hline módulo de Young & $\mathrm{N} / \mathrm{mm}^{2}$ & $700-1000$ & \\
\hline densidad aparente & $\mathrm{Kg} / \mathrm{m}^{3}$ & $1900-2200$ & $1700-$ \\
\hline coeficiente de expansividad térmica & $\mathrm{mm} / \mathrm{m}^{\circ} \mathrm{C}$ & $0,010-0,015$ & \\
\hline hinchamiento tras inmersión 24 horas & $\mathrm{mm} / \mathrm{m}^{\circ} \mathrm{C}$ & $0,5-1$ & $1-2$ \\
\hline retracción por secado & $\mathrm{mm} / \mathrm{m}^{\circ} \mathrm{C}$ & $0.2-1$ & $0,2-1$ \\
\hline permeabilidad & $\mathrm{mm} / \mathrm{sec}$ & $1,10-5$ & \\
\hline absorción de agua total & $\%$ del peso & $5-10$ & $10-20$ \\
\hline calor específico & $\mathrm{KJ} / \mathrm{Kg}$ & 0,85 & $0,65-0,85$ \\
\hline coeficiente de conductividad térmica & $\mathrm{W} / \mathrm{m} \circ \mathrm{C}$ & $0,46-0,81$ & $0,81-0,93$ \\
\hline coeficiente de transmisión de vapor & $\%$ & $5-10$ & $10-30$ \\
\hline desfase térmico & $\mathrm{horas}$ & $10-12$ & $5-10$ \\
\hline aislamiento acústico muros de $40 \mathrm{~cm}$ & $\mathrm{~dB}$ & 50 & 40 \\
\hline
\end{tabular}

postura arquitectónica que plantea la obra desde el tacto, el olfato y el gusto, tal como los enólogos degustan el vino.

La masa térmica de los adobes contribuye al control térmico dentro de las bodegas y sus cualidades acústicas permiten el uso de algunos espacios como salas de presentación o de cata de vinos.

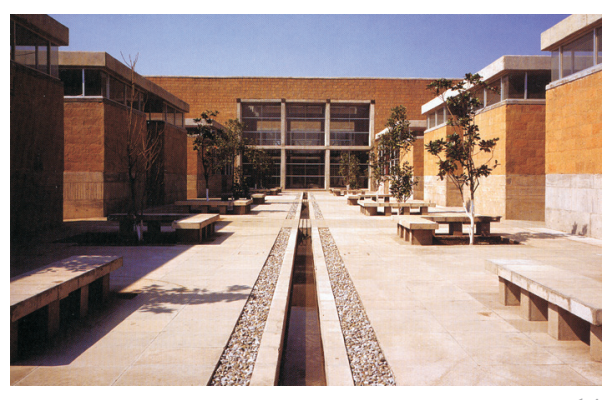

14. Muros de btc y zócalos de hormigón en el Centro para la Atención de Gente Invidente, ciudad de México, México. Fuente: Mauricio Rocha

15. Límite líquido. Áreas recomendadas para adobe, tapial, BTC. (1) AFNOR, 2001 (2) CDI 1998 (3) MOPT 1992 (4) Houben 1994. (5) Rigassi 1995. Fuente: Ignacio Cañas

16. Tamaño de partículas. Áreas re comendadas para adobe, tapial, BTC (1) AFNOR, 2001 (2) CDI 1998 (4) Houben 1994. Fuente: Ignacio Cañas
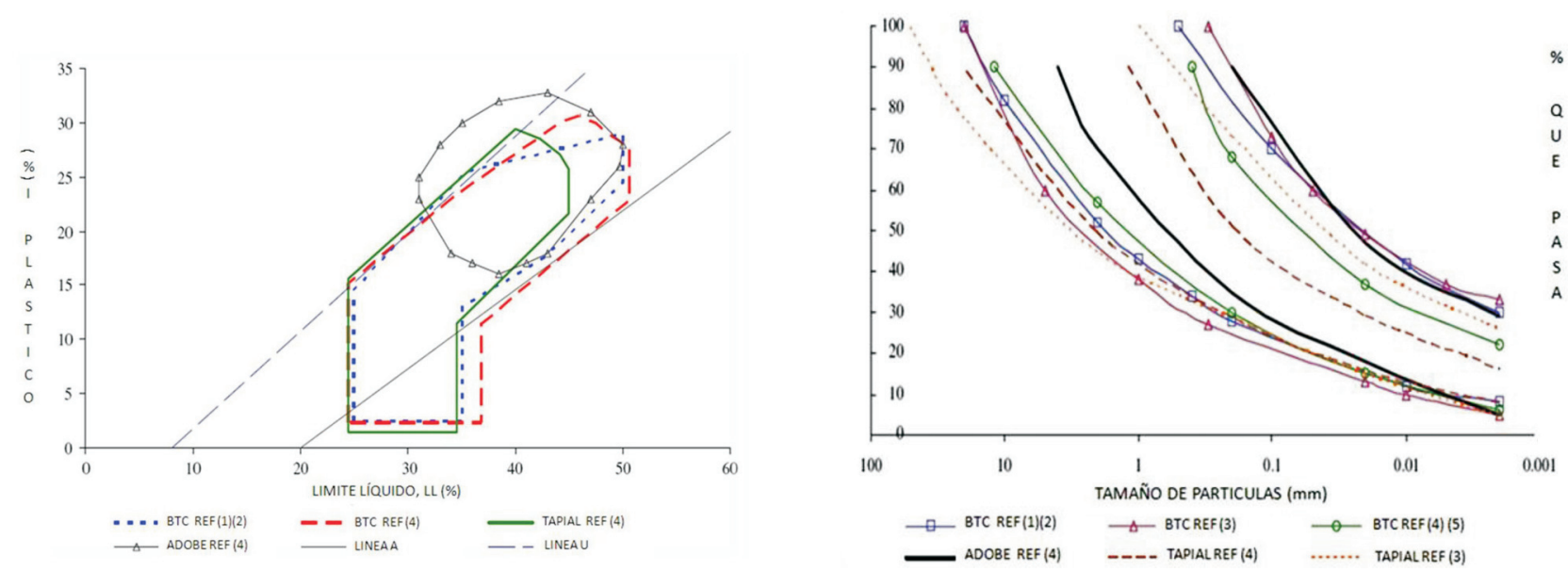
17. Muros de adobe protegidos por los aleros de la cubierta y los zócalos de hormigón y piedra en la Bodega Los Robles, San Fernando, Chile. Fuente: José Cruz Ovalle
Las construcciones de tierra deben protegerse frente a los efectos de la humedad del terreno, así como de las precipitaciones. La colocación de barreras anti-humedad en el detalle de las cimentaciones previene de la ascensión por capilaridad. La penetración de filtraciones debido a las precipitaciones está limitada por el grado de absorción y disipación de los paramentos.

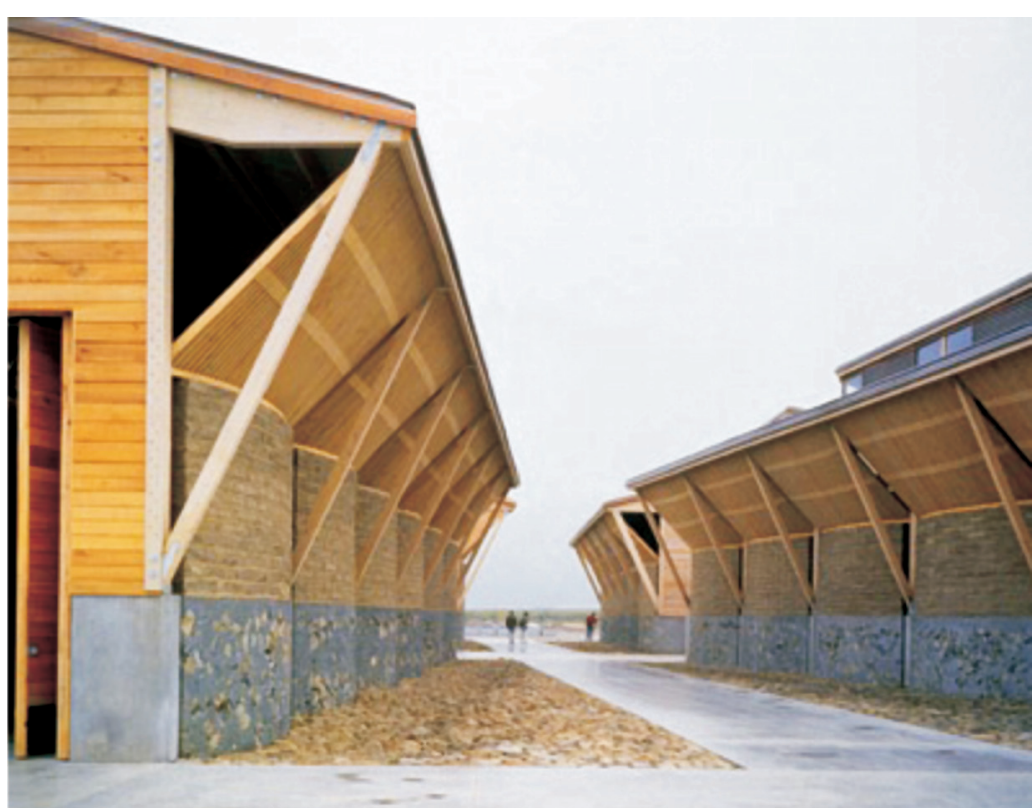

En las épocas secas la humedad absorbida por los muros es devuelta a la atmósfera gracias a la capacidad transpirable de los muros de tierra. Aún así, generalmente el nivel de exposición de las paredes a las inclemencias se reduce mediante aleros y zócalos para disminuir su erosión. Otra opción es la protección directa mediante revestimientos permeables al vapor que reduzcan la exposición directa del muro. Sin embargo, no se recomienda la aplicación de revestimientos impermeables que afecten a la transpirabilidad del muro.

2003 Universidad Indígena Chiquitana, San Ignacio de Velasco, Bolivia. Arquitectos: Sandra Bestraten Castells y Emilio Hormías Laperal, Càtedra Unesco de Sostenibilitat UPC, Universitat Sense Fronteres. Premios:

- 2005 Finalista de ArCatMón Arquitectura Catalana en el Mundo del Colegio de Arquitectos de Cataluña.

- 2001 Concurso Nacional de Proyectos de Final de Carrera de Ingenieros Sin Fronteras y Centros de cooperación de Universidades de España.

La Universidad Indígena de la Chiquitanía forma parte del programa Educación para el Desarrollo-Bolivia coordinado desde las asignaturas "Vivienda y Cooperación" y "Tecnologías de bajo coste para la Coo- peración" de la Escola Tècnica Superior d'Arquitectura de Barcelona (ETSAB) de la Universidad Politécnica de Catalunya. El programa impulsa la mejora de las técnicas de construcción locales. Los proyectos son desarrollados por voluntariado de la universidad. La transferencia de tecnología se consigue con la participación directa de la población local en la ejecución del edificio.

Este edificio supone una actualización de las técnicas de la arquitectura tradicional del oriente boliviano basado en los materiales autóctonos: el adobe y la madera. Rescatando las bondades de la construcción con tierra, en crisis debido a la imagen de modernidad y progreso del hormigón, el ladrillo y el acero, el edificio realza su valor educativo y consituye un referente de la identidad regional.

La combinación de muros de adobe de $40 \mathrm{~cm}$ de grosor que soportan la estructura de cubierta de cerchas de madera, con la incorporación de grandes lucernarios que permiten una ventilación por efecto Venturi, mejora la tipología tradicional aportando confort térmico y visual con un coste energético cero.

La misma arcilla roja extraída de la excavación de las cimentaciones se utilizó para la producción in situ de los adobes de 40 × 20 × $10 \mathrm{~cm}$.

La estructura de cubierta, de 7 metros de luz, consiste en cerchas de madera que se apoyan en las vigas collar de madera que reparten la carga y la transmiten de forma homogénea a los muros de adobe.

El edificio está situado en una zona subtropical con una época de intensas lluvias. Para reducir el trabajo de mantenimiento se ha optado por la colocación de grandes aleros y porches. Además, los muros van revestidos con un revoco de tierra y cal. La primera fase se realizó entre 2003 y 2004 con un coste del edificio final de $50 € / \mathrm{m}^{2}$.

Una vez finalizada la construcción se realizaron mediciones comparativas del confort térmico y lumínico dentro de las aulas de la Universidad y de una escuela convencional para evaluar las mejoras alcanzadas.

Los resultados mostrados en las siguientes tablas muestran cómo la utilización del adobe reduce el salto térmico en comparación con un aula de un edificio convencional de ladrillo cocido en la misma orientación óptima norte-sur y de la misma tipología con porche en la fachada soleada. Aunque la instrumentalización se realizó en días distintos sí se puede constatar el comportamiento general de las distintas tecnologías. 
Analizando las temperaturas de contacto en la superficie del muro en la fachada oeste de la Universidad, se aprecia que mientras que en el exterior se registra instrumentalmente un salto térmico de $25^{\circ} \mathrm{C}$, en el interior se reduce a un salto térmico de únicamente $10{ }^{\circ} \mathrm{C}$, manteniendo mucho más estable la temperatura. La temperatura mínima en el exterior alcanza los $16{ }^{\circ} \mathrm{C}$ pero en el interior nunca es inferior a $19{ }^{\circ} \mathrm{C}$. La temperatura máxima en el exterior de $41{ }^{\circ} \mathrm{C}$ mientras que en el interior no alcanza los $29^{\circ} \mathrm{C}$.

El comportamiento térmico de los muros de tierra mejora en gran medida con el efecto de la masa térmica debido al efecto del desfase térmico (16).

Desfase

$\mathrm{d}(\mathrm{h})=0,53 \times \mathrm{T} / 2 \times \sqrt{ }(\rho \times \mathrm{Ce} / \varpi \times \lambda \times \mathrm{T}) \times \mathrm{L}$

Donde :

$$
\begin{aligned}
& \mathrm{T}=\text { período de cálculo }(24 \mathrm{~h}) \\
& \rho=\text { densidad }\left(\mathrm{kg} / \mathrm{cm}^{3}\right) \\
& \text { Ce }=\text { Calor específico }\left(\mathrm{kj} / \mathrm{kg}^{\circ} \mathrm{C}\right) \\
& \varpi=3,1416 \\
& \lambda=\text { conductividad térmica }\left(\mathrm{w} / \mathrm{m}^{\circ} \mathrm{C}\right) \\
& \mathrm{L}=\text { grueso del muro }(\mathrm{m})
\end{aligned}
$$

En la escuela de ladrillo, sin embargo, los datos de temperatura de contacto en la superficie de la fachada oeste, muestran que mientra en el exterior el salto térmico es de $16{ }^{\circ} \mathrm{C}$, la inercia del muro de ladrillo únicamente consigue rebajarlo a $13^{\circ} \mathrm{C}$. Sorprendentemente hace más calor en el interior del aula, generando un ambiente fuera del ámbito de confort que dificulta la concentración de los estudiantes.

Cuando en el exterior la temperatura ambiente aumenta y la humedad relativa disminuye, el edificio de adobe actúa mediante el mecanismo de refrigeración por evaporación y aumenta la humedad relativa interior en comparación con el exterior para lograr reducir la temperatura ambiente.

En cambio, en la escuela de ladrillo se observa cómo la poca amortiguación térmica coincide con la poca diferencia de humedad entre interior y exterior. Se constata que el edificio de ladrillo no realiza el mecanismo de control higrotérmico.
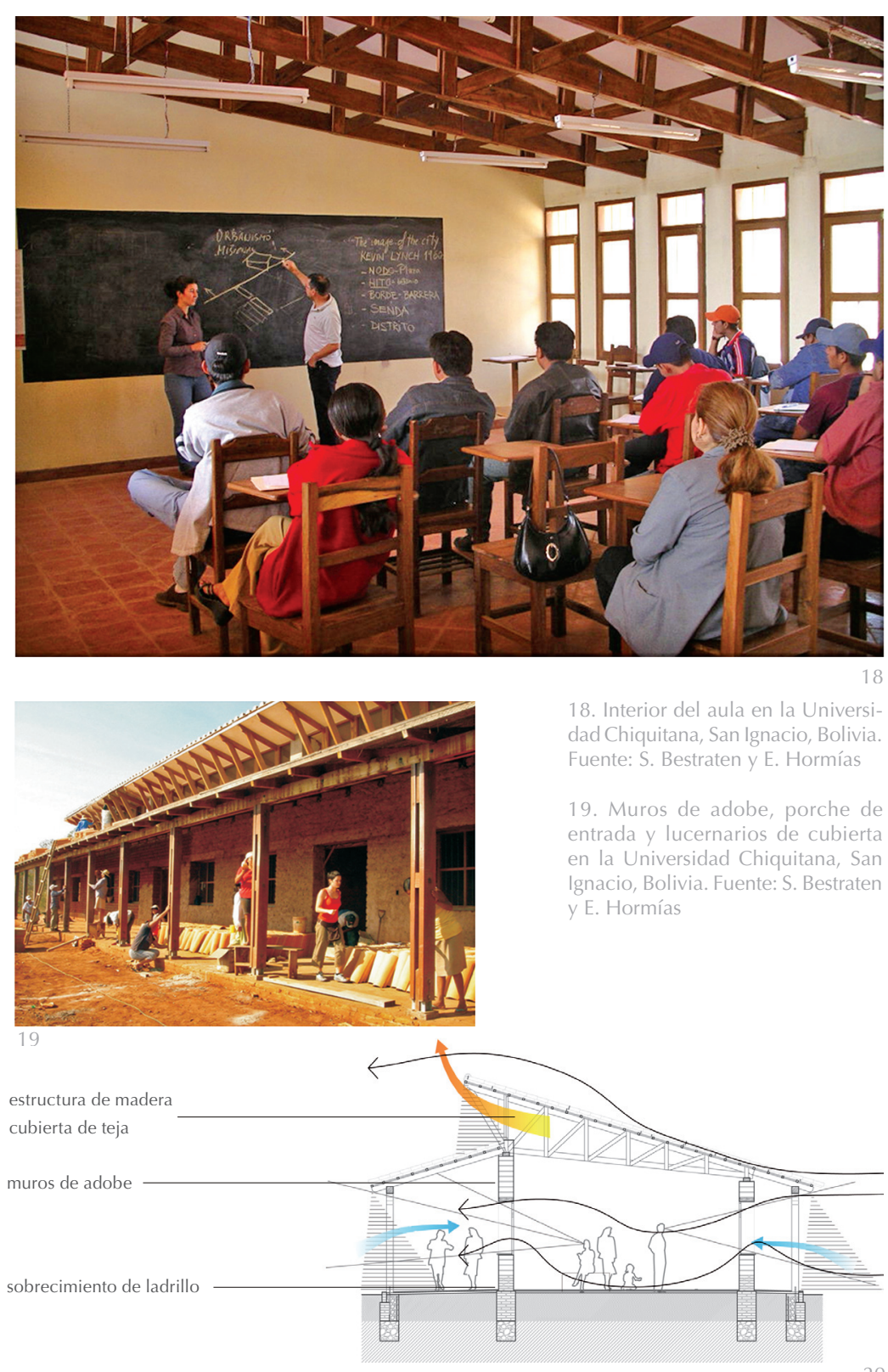

20

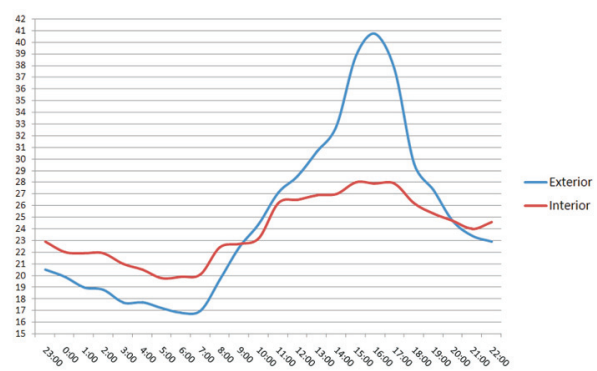

20. Sección de la Universidad Chiquitana, San Ignacio, Bolivia. Fuente: S. Bestraten y E. Hormías

21. Temperatura de contacto Int-Ex UCHI (adobe). Fuente: S. Bestraten y E. Hormías

22. Temperatura de contacto Int-Ext Escuela (ladrillo). Fuente: S. Bestraten y E. Hormías

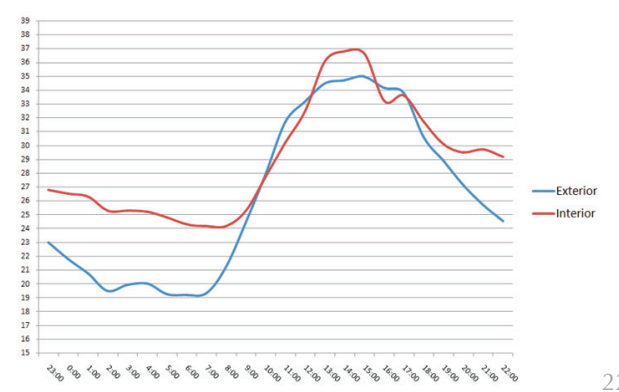


23. Muros de adobe y aberturas con celosías en el edificio para la asociación Yeredemé, Mopti, Mali. Fuente: Fernando Martín Consuegra

24. Detalle constructivos de la galería del edificio para la asociación Yeredemé, Mopti, Mali. Fuente: Francisco Botella

25. Detalle constructivos de la cubierta del edificio para la asociación Yeredemé, Mopti, Mali. Fuente: Francisco Botella
2005 Edificio para la asociación Yeredemé de apoyo a jóvenes madres solteras, Taikiré, Mopti, Mali. Arquitectos: Fernando Martín Consuegra, Francisco Botella.

Premios:

- Concurso EcoHabitat 2005

El edificio se construyó en Mopti por encargo de la asociación de madres solteras Yeredemé. Los arquitectos forman parte de la Cátedra Unesco de Habitabilidad Básica dirigida por Julián Salas, de la Universidad Politécnica de Madrid.

El propósito de los arquitectos en la elección del sistema constructivo fue aprovechar las técnicas constructivas tradicionales del lugar, óptimas en los aspectos de confort interior, y a la vez crear un referente duradero y alternativo a la construcción en hormigón. Partiendo de la construcción en adobe y ma-
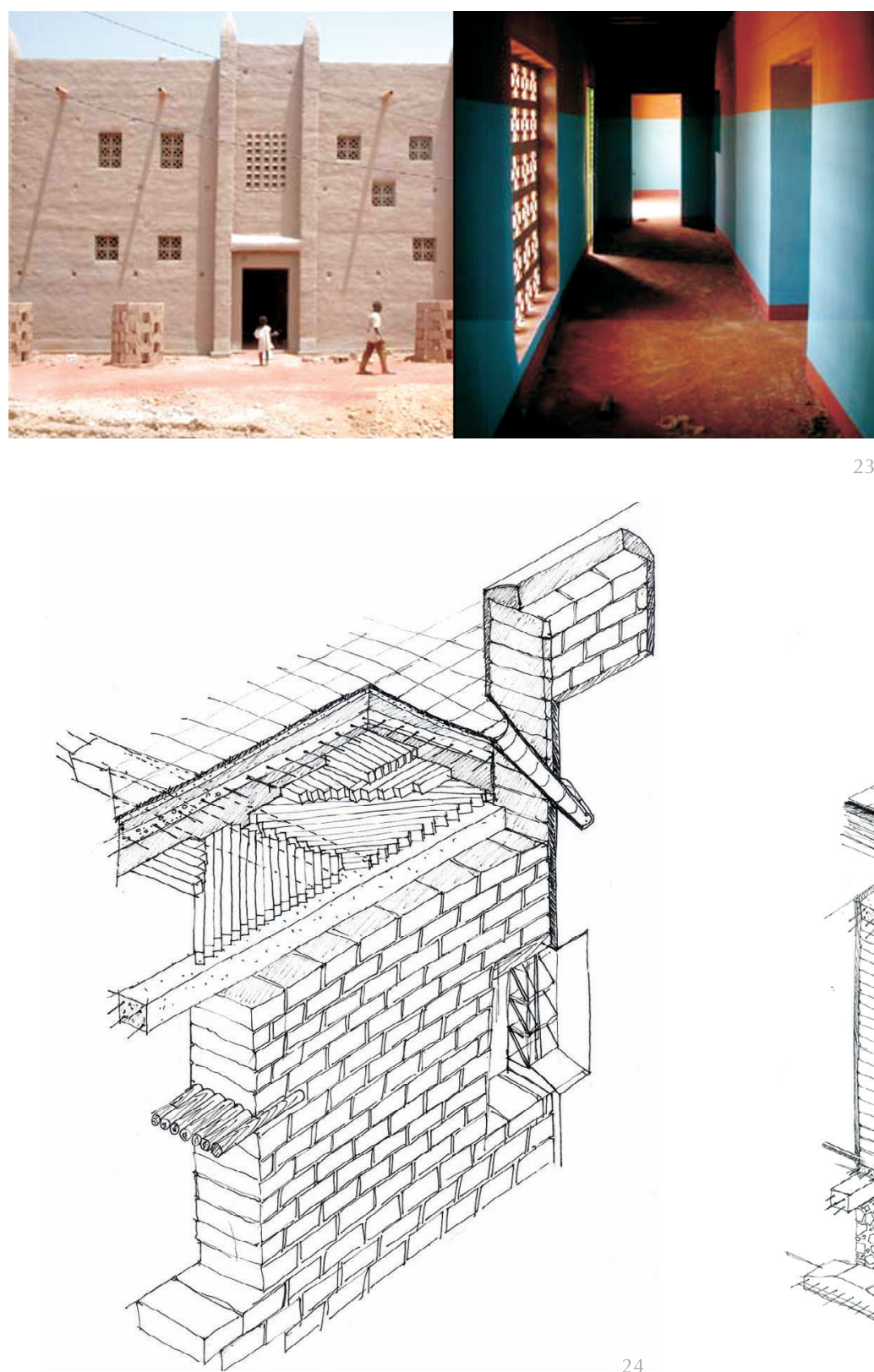

dera, técnicas tradicionales arraigadas en la sociedad de Mali, los arquitectos han aportado innovaciones coherentes para aunar las cualidades económicas, sostenibles y de durabilidad.

Para reducir el espesor de los muros éstos se diseñaron en planta de manera que se equilibraran las fachadas interior y exterior mediante los muros perpendiculares a fachada, y se construyó un zuncho de hormigón armado en las cabezas de los muros. Este zuncho permite abrir grandes huecos en las fachadas a patio, y distribuye la carga de las vigas metálicas que disminuyen la luz del forjado.

Los forjados se construyen en madera de palmera, con capa de compresión de barro. Se utilizan vigas metálicas para poder reducir su escuadría.

La impermeabilización de la cubierta se realiza con arcillas expansivas. Este sistema es efectivo en las condiciones de clima extremo de Mali al cerrarse las fisuras cuando se hidrata con la lluvia. Se utiliza como acabado baldosa de barro cocido para evitar el lavado de la arcilla y permitir el uso público de las azoteas.

En el revestimiento de los muros se utiliza el crepissage tradicionnel, consistente en una mezcla fermentada de barro y paja. La protección de barro permite proteger la estructura de adobe, al ser fácilmente reponible cada dos años con mano de obra y materiales locales. La superficie construida total es de $340 \mathrm{~m}^{2}$ y el coste de la edificación fue de $88 € / \mathrm{m}^{2}$ en 2005.

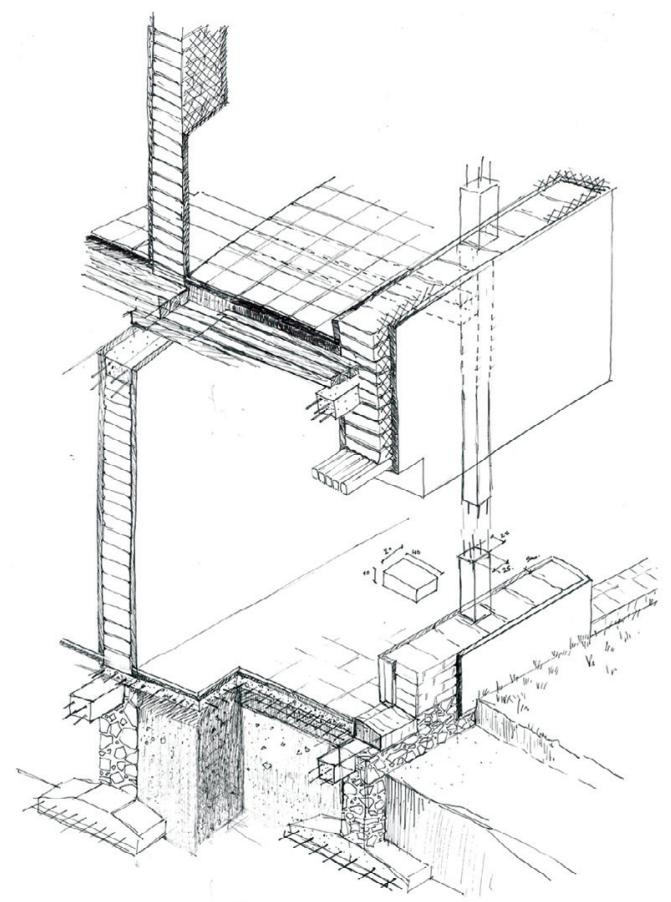




\subsection{Cob}

La técnica del cob consiste en una masa de barro y abundante paja que se apila y moldea a mano para formar muros monolíticos. La composición del material es parecida al adobe, pero el moldeado se realiza directamente en el muro sin previo confinamiento en un paralelepípedo.

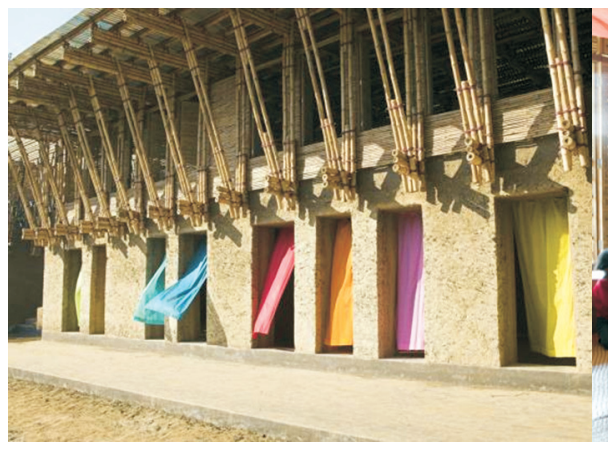

2005 Handmade School, Rudrapur, Bangladesh. Arquitectas: Anna Heringer y Eike Roswag. Asesoramiento en la construcción: Lehm Ton Erde Martin Rauch.

Premios:

- Architectural Review Awards for Emerging Architecture

- Aga Khan Award

Este edificio forma parte del programa BASEhabitat de la factultad de Arquitectura de la Universidad de Arte de Linz, Austria. BASEhabitat ha realizado una serie de proyectos de cooperación basados en la eficiencia energética, el carácter local de los materiales y la sostenibilidad social de los edificios. Fue el proyecto final de carrera de la arquitecta Anna Heringer y fue construido en 2005 bajo la supervisión del experto Martin Rauch.

La construcción de esta escuela en Rudrapur hace una novedosa interpretación de las tradiciones en construcción con tierra de esta región de Bangladesh. La naturaleza plástica de la técnica del cob permitió a las arquitectas diseñar espacios cueva para los juegos de los alumnos de la escuela. En el interior de estos espacios orgánicos, íntimos, táctiles, los niños pueden estudiar, reunirse en pequeños grupos, dormir o jugar.

La planta baja consta de gruesos muros de cob, mientras que la segunda planta se construye con ligeras estructuras de bambú abiertas a las vistas, como una gran cubierta ventilada.

En estos tres anteriores ejemplos de proyectos de cooperación en América, África y Ásia, queremos destacar la calidad arquitectónica de los mismos, convirtiendo los equipamientos en referentes que permitan recuperar la consciencia y credibilidad de los edificios en tierra como solución viable a nivel económico, social y ambiental. La recuperación de esta consciencia es necesaria ya que, aunque el extenso patrimonio de tierra todavía está en pie, éste tiende a desaparecer; no por falta de estabilidad, sino por el cambio de mentalidad de sus propietarios y falta de confianza en lo local.

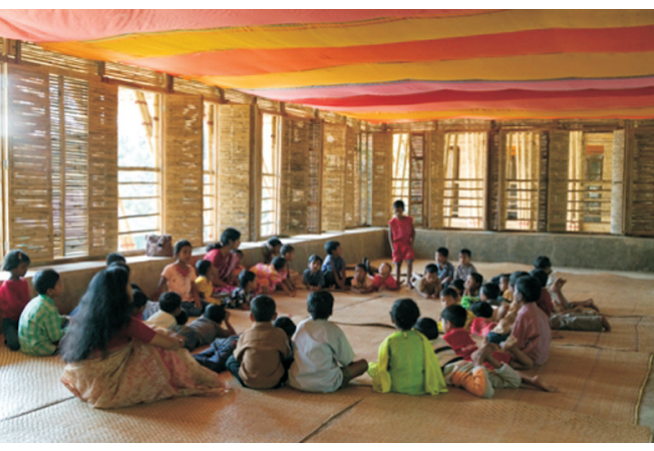

2002 Pabellón de Servicios de Cob en Eden Project, Cornwall, Reino Unido. Arquitectas: Jackie Abey y Jill Smallcombe.

El cob es un sistema tradicional de construcción con tierra utilizado durante cientos de años en el sudeste del Reino Unido. Para las arquitectas Jill Smallcombe y Jackie Abbey, el cob es una técnica con cualidades esculturales excepcionales. Su textura y resistencia les ha permitido explorar en cuestiones de forma, ligereza, escala y contraste. Realzando sus cualidades orgánicas, el pabellón de servicios en el Eden Project se realizó con muros curvados de cob, protegidos debidamente con un zócalo y el gran alero de la cubierta de captación solar.
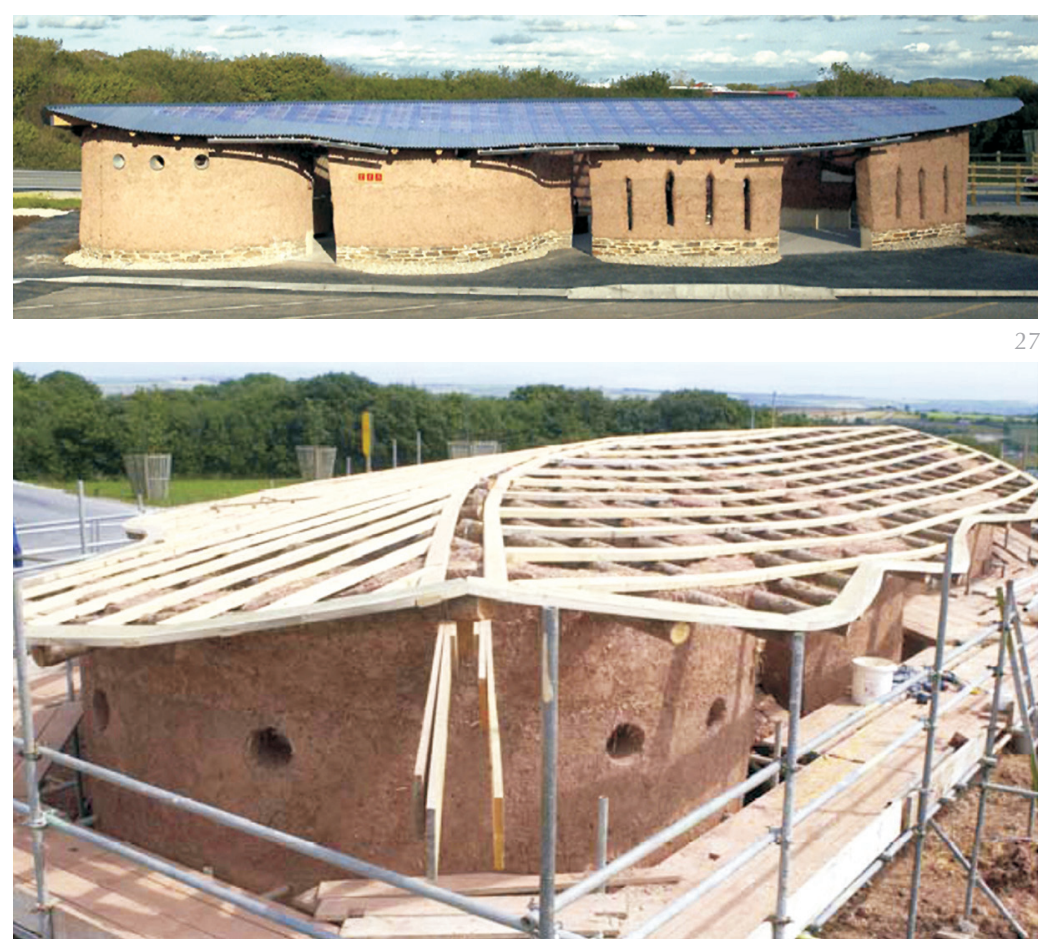

26. Muros de cob y cubierta de bambú en la Handmade School de Rudrapur, India. Fuente: BASEhabitat

27. Muros de cob y cubierta captadora de energía solar térmica en el Pabellón de Servicios del Eden Project, cornwall, Reino Unido. Fuente: Abey Smallcombe

28. Muros de cob y estructura de cubierta en el Pabellón de Servicios del Eden Project, Cornwall, Reino Unido. Fuente: Abey Smallcombe 
Se decidió fabricar una mezcla de la arcilla de caolín y arcilla roja de Devon que se sabía que era mucho más duradera. El cob consistía en una mezcla de un $40 \%$ caolín y $60 \%$ de arcilla roja de Devon. La arcilla de caolín venía de restos del pozo de Imerys en Melbur. La arcilla roja Devon fue extraida de las excavaciones de un vertedero a las afueras de Crediton. El material es la combinación de dos materiales residuales de la zona.

La mezcla de arcillas se humedeció hasta alcanzar la plasticidad necesaria y se mezcló mecánicamente. Posteriormente se agregó a la mezcla aproximadamente un $2,1 \%$ de paja de cebada. Según los ensayos realizados, el cob inicial tenía una densidad de $1.890 \mathrm{~kg} / \mathrm{m}^{3}$ con una cantidad de agua de aproximadamente el $15 \%$.

El cob contiene una alta proporción de arciIla, alrededor del 21\%, lo que normalmente da lugar a cantidades excesivas de retracción. Sin embargo, debido a la gran cantidad de agregados que figuran en el arcilla roja, la retracción se redujo drásticamente a un $4,1 \%$; resultando un cob con una densidad final de alrededor de $1.615 \mathrm{~kg} / \mathrm{m}^{3}$.

El edificio terminado contiene aproximadamente 91 metros cúbicos de cob. Las paredes tienen una masa húmeda de $171.500 \mathrm{~kg}$ y una vez seca una masa de $146.500 \mathrm{~kg}$. El cob se considera generalmente que tiene una capacidad máxima de carga de alrededor de $1 \mathrm{~N} / \mathrm{mm}^{2}$ en el punto más alto de la pared la base tiene una carga de $0,052 \mathrm{~N} / \mathrm{mm}^{2}$ debido a su peso y por lo tanto puede tener una carga considerable de sobrecargas como la estructura de techo o de otro tipo.

\section{CRITERIOS DE SOSTENIBILIDAD QUE OFRECE LA TIERRA}

La construcción con tierra en el siglo XXI se apoya en los criterios de sostenibilidad. La tierra ofrece una gran oportunidad de reducir el impacto ambiental de la edificación, y por tanto creemos conveniente enumerar sus cualidades para potenciar su valor.
La fuente de abastecimiento del material es ilimitada. Analizando los tipos de tierra se pueden incorporar mejoras a nivel granulométrico y de composición. También permite incorporar la posibilidad de utilizar tierra de las propias excavaciones, favoreciendo la reducción de residuos de la obra y los gastos de transporte de material.

Los procesos de producción son sencillos, sin necesidad de cocciones que generan combustiones con un alto consumo energético. A diferencia de los ladrillos o el hormigón, la energía utilizada en la producción es muy baja. Además no se producen emisiones tóxicas durante el proceso de transformación ni durante su vida útil.

El lugar de extracción puede ser el mismo emplazamiento de la obra, de forma que el impacto ambiental durante el transporte y el impacto paisajístico en la producción se reduce a cero.

El consumo de agua en la producción y en la obra es especialmente bajo en el tapial y BTC donde la tierra se trabaja con una humedad cercana al $10 \%$.

Los restos de material desechados (piezas rotas o sobrantes) se pueden reintegrar en el mismo emplazamiento, sin generar residuos, reduciéndose éstos a los posibles embalajes.

La demolición de un elemento de tierra se puede realizar con medios mecánicos, aunque sin precisar de energía excesiva. No necesita ningún tratamiento para ser devuelto al medio ambiente sin causar contaminación alguna.

En caso de un material estabilizado con cemento o cal, la proporción del estabilizante (5-10\%) es suficientemente baja como para no suponer ningún riesgo para ningún entorno natural. Ello permite la regeneración de la masa vegetal.

Una de las variables habituales en el análisis de la sostenibilidad de los materiales de construcción consiste en el cálculo de las emisiones de $\mathrm{CO}_{2}$. A continuación exponemos algunas

Tabla 8

Emisiones $\mathrm{CO}_{2}$ de los distintos materiales *fuente: (elaboración propia a partir de 16,17)

\begin{tabular}{|c|c|c|c|}
\hline material & densidad & emisiones por $\mathbf{k g}$ & emisiones por $\mathrm{m}^{3}$ \\
\hline tapial (sin estabilizar) & $2.200 \mathrm{~kg} / \mathrm{m}^{3}$ & $0,004 \mathrm{~kg} \mathrm{CO}_{2} / \mathrm{Kg}$ & $9,7 \mathrm{~kg} \mathrm{CO} / 2 \mathrm{~m}^{3}$ \\
\hline adobe & $1.200 \mathrm{~kg} / \mathrm{m}^{3}$ & $0,06 \mathrm{~kg} \mathrm{CO}_{2} / \mathrm{Kg}$ & $74 \mathrm{~kg} \mathrm{CO}_{2} / \mathrm{m}^{3}$ \\
\hline hormigón en masa in situ & $2.360 \mathrm{~kg} / \mathrm{m}^{3}$ & $0,14 \mathrm{~kg} \mathrm{CO}_{2} / \mathrm{Kg}$ & $320 \mathrm{~kg} \mathrm{CO} / 2 \mathrm{~m}^{3}$ \\
\hline $\begin{array}{l}\text { hormigón prefabricado, } 2 \% \text { de } \\
\text { acero }\end{array}$ & $2.500 \mathrm{~kg} / \mathrm{m}^{3}$ & $0,18 \mathrm{~kg} \mathrm{CO} / 2 / \mathrm{Kg}$ & $455 \mathrm{~kg} \mathrm{CO} / 2 \mathrm{~m}^{3}$ \\
\hline pared de ladrillo macizo & $1.600 \mathrm{~kg} / \mathrm{m}^{3}$ & $0,19 \mathrm{~kg} \mathrm{CO}_{2} / \mathrm{Kg}$ & $301 \mathrm{~kg} \mathrm{CO} 2 / \mathrm{m}^{3}$ \\
\hline pared de ladrillo hueco & $670 \mathrm{~kg} / \mathrm{m}^{3}$ & $0,14 \mathrm{~kg} \mathrm{CO}_{2} / \mathrm{Kg}$ & $95 \mathrm{~kg} \mathrm{CO} / 2 \mathrm{~m}^{3}$ \\
\hline
\end{tabular}


cifras sobre emisiones de $\mathrm{CO}_{2}$ asociadas a la construcción convencional con hormigón u obra de fábrica, y de construcción con tierra, procedentes de estudios realizados en diferentes universidades $(16,17)$. La comparativa muestra claramente cómo la tierra emite una cantidad muy reducida de $\mathrm{CO}_{2}$ en comparación con los materiales convencionales.

\section{CONCLUSIONES}

La arquitectura en tierra constituye un extenso patrimonio cultural que ha transcendido el paso del tiempo con edificios de centenares de años de existencia. Culturas milenarias emplearon la tierra como solución en todo tipo de estructuras de tierra, cuyos vestigios aun perduran.

Los ejemplos citados de arquitectura contemporánea, ampliamente reconocidos y premiados, manifiestan la viabilidad técnica, estética y económica de la tierra como material actual de construcción.

\subsection{Un sector emergente global}

La búsqueda de nuevos materiales de construcción que aportan nuevas soluciones, sumado a la voluntad de hacer una arquitectura cada día más sostenible ha hecho emerger un material que se fue abandonando a lo largo del siglo XX. La sociedad y los técnicos han vuelto la mirada hacia la tierra que reivindica su lugar en una nueva cultura. Este resurgir como material más ecoógico todavía no es generalizado pero sin duda alguna se da en todo el mundo. No se localiza en una área geográfica concreta y su uso está claramente en expansión entre los países desarrollados. Este hecho es un incentivo para los países en vías de desarrollo, con una mirada atenta a recuperar su identidad constructiva.

Por ello, es necesario divulgar ampliamente los conocimientos sobre estas técnicas, no sólo en la edificación de obra nueva, sino también en el campo de la rehabilitación. Es muy habitual encontrar edificios donde es necesario ampliar métodos definidos de análisis, peritaje e intervención.

\subsection{Las claves técnicas}

Cada material resuelve sus dificultades o limitaciones técnicas mediante el diseño apropiado. Así pues, no es lógico adaptar las soluciones formales de la concepción del hormigón armado a las técnicas de construcción con tierra aunque puedan tener elementos en común. Los encofrados de la industria del hormigón han representado una importante mejora para la ejecución de las tapias de tierra compactada, pero éstos han tenido que adaptarse ya que deben poder soportar empujes de

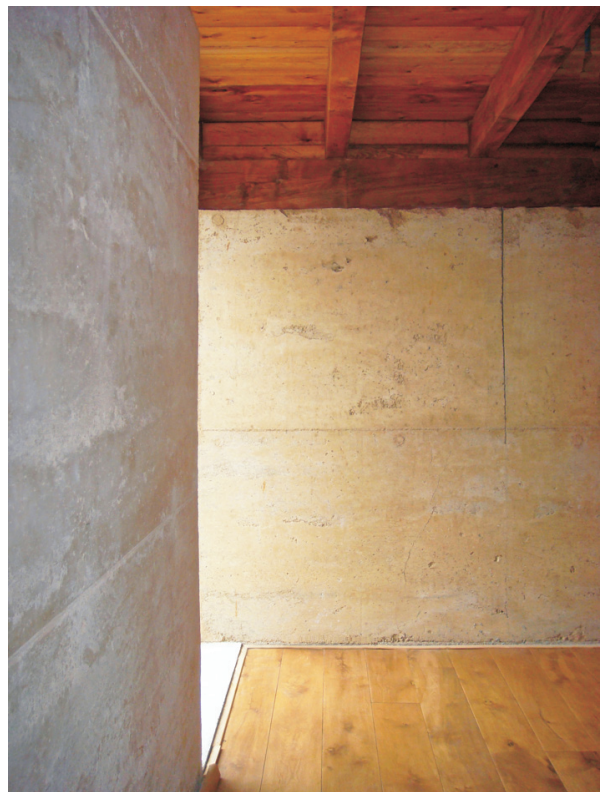

29. Muro de tapial en vivienda. Riudarenes, Girona, España. Fuente: S. Bestraten y E. Hormías compactación. Sin embargo, las imágenes de grandes paños de muro de hormigón expuestas a las inclemencias meteorológicas no son directamente trasladables a los muros de tapia excepto en climas extremadamente áridos.

El entendimiento de los puntos fuertes y débiles del material nos llevará a una concepción apropiada del edificio que proteja la base de los muros, limite su exposición directa al agua, prevea juntas de retracción, limite la concentración de cargas, entre algunos aspectos a tener en consideración en este tipo de construcción.

\subsection{El futuro}

La ausencia de industria que desarrolle estas tecnologías es una limitación para el avance en el uso de estas técnicas de tierra.

Así pues, el camino de la construcción con tierra de hoy en adelante, pasa por trabajar en la investigación en varios campos: la industrialización y mecanización para la optimización de procesos; la adición de materiales que aporten estabilización y protección frente a la humedad; la introducción de aligerantes que no comprometan la resistencia del material; y las posibilidades de incorporación de residuos de diferentes industrias (cenizas volantes, escorias siderúrgicas, escombros de obras).

El futuro próximo de la construcción con tierra pasa también por el establecimiento de una normativa así como de controles pertinentes de calidad, no solo del material sino también de su proceso ejecución, que permita finalmente incorporar este material, la tierra, en los currículums de docencia universitaria y en la práctica constructiva habitual de cualquier profesional. 


\section{BIBLIOGRAFÍA}

(1) Algorri, E.: "La construcción con tierra en el Código Técnico de la Edificación". Más es menos, Construir en Barro. Una Arquitectura de Futuro (2009). Centro de Estudios Benaventanos Ledo del Pozo. ISBN: 978-84-936651-4-2.

(2) Rauch, M.; Kapfinger, O.: Rammed Earth, Lehm un Architektur. Ed. Birkhäuser, Basel, 2001. ISBN 3-7643-6461-0.

(3) Maldonado, L.; Vela Cossío, F.; Hoz, J.: Diccionario de construcción tradicional. Tierra. Editorial Nerea, San Sebastián, 2003. ISBN: 84-89569-80-0.

(4) Bauluz, G.; Bárcena, P.: Bases para el diseño y construcción con tapial. Ministerio de Obras Públicas y Transportes, Madrid, 1992. ISBN 8474338395.

(5) Smallcombe, J.; Abey, J.: "Cob bus shelter at the Eden Project". Devon Earth Building Association newsletter, Issue spring (2005), pp. 5-9.

(6) Normativa de construcción con tierra neozelandesa NZ 4297:1998.

(7) Ficha técnica del Bloque BTC Bioterre, fabricante: Grup Planas.

(8) Font, F.; Hidalgo, P.: Arquitecturas de Tapia. Col.legi Oficial d'Aparelladors i Arquitectes Tècnics de Castelló, Castellón, 2010. ISBN 978-84-613-3143-7.

(9) Walker, P.; Keable, R.; Martin, J.; Maniatidis, V.: Rammed Earth, Design and construction guidelines. Ed. BRE Bookshop, 2005. ISBN 1-86081-734-3.

(10) Rael, R.: Earth architecture. Ed. Princeton Architectural Press, Nueva York, 2009. ISBN 978-1-56898767-5.

(11) Guigou, C.: La tierra como material de construcción. Colegio Oficial de arquitectos de Canarias, 2002. ISBN: 84-600-9721-8.

(12) Domínguez Alonso, M.: "Propiedades térmicas de los adobes". Ponencia presentada en el IX Encuentro Internacional de Trabajo Navapalos, (1994). Publicado en Arquitectura de tierra. Encuentros Internacionales de Navapalos. Centro de Publicaciones Ministerio de Fomento, Madrid, 1999. ISBN 84-498-0387-X

(13) Catálogo de soluciones cerámicas. Hyspalit e Instituto de Ciencias de la Construcción Eduardo Torroja, Madrid, 2008. Dep. legal M-41050-2008.

(14) Código técnico de la edificación. Código Técnico de la Edificación. Real Decreto 314/2006. Ministerio de Vivienda. DBSI.

(15) Código técnico de la edificación. Código Técnico de la Edificación. Real Decreto 314/2006. Ministerio de Vivienda. DBHR.

(16) Bobes, A.: Les eines del bioclimatisme. Escola Sert, Barcelona, 2007.

(17) Hegger, M.; Auch-Schwelk, V.; Fuchs, M.; Rosenkranz, T.: Construction materials manual. Ed. Birkhäuser, Basel, 2005. ISBN-10: 3-7643-7570-1. 